Review Article

\title{
PATHOPHYSIOLOGY, MECHANISM AND MANAGEMENT OF OVERACTIVE BLADDER SYNDROME-A REVIEW
}

\author{
PANKAJ MANDPEa,b, BALA PRABHAKAR ${ }^{a}$
}

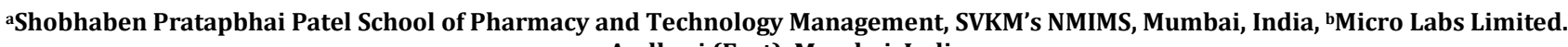
Andheri (East), Mumbai, India

Email: pankajmandpe@gmail.com

Received: 03 Feb 2018 Revised and Accepted: 01 Jun 2018

\begin{abstract}
An overactive bladder $(\mathrm{OAB})$ is a syndrome which causes an impulsive desire to pass the urine. This desire or urge may become difficult to control and eventually may lead to unintentional passage of urine. The marked increase in a number of patients who suffered with OAB feels very awkward and tries to isolate from societal-life. Such increase in a number of patients has drawn an attention of scientists to research on this area. The proper diagnosis and management of $\mathrm{OAB}$ can help the patient to get early relief and cure the symptoms. Looking at the rate of prevalence of $\mathrm{OAB}$ in patients, it is essential to understand the pathophysiology, available treatment and recent updates to direct the researchers for further investigation. This review article focuses on comprehensive information of normal bladder physiology, neural control, regulation of micturition, pathophysiology, and prevalence of overactive bladder. This article gives an information regarding diagnosis, different approaches for treatments and future perspective of $\mathrm{OAB}$ syndrome.
\end{abstract}

Keywords: Overactive bladder, Neural control, Detrusor muscle, Worldwide prevalence, Invasive therapies

(C) 2018 The Authors. Published by Innovare Academic Sciences Pvt Ltd. This is an open access article under the CC BY license (http://creativecommons.org/licenses/by/4.0/) DOI: http://dx.doi.org/10.22159/ijpps.2018v10i7.25114

\section{INTRODUCTION}

Since the last two decades, people suffering from OAB syndrome/ symptom has increased enormously worldwide and is anticipated that it will cross 546 million populations by 2018 . The annual worldwide healthcare cost for $\mathrm{OAB}$ is enhanced from $€ 1.4$ trillion to $€ 3.2$ trillion by 2018 . Though the percentage of both male and female patients is most similar it is slightly more in women population [1]. In the initial phase of OAB syndrome, individual may not understand the indication of urine urgency which may occure due to the large volume of liquid intake, any physical exertion, stress-induced or any other defect occurred in the body functioning. At the initial stage, it is very difficult for both patient and physician to identify the symptoms of OAB [2]. Thus, making a note on the diary with date and time with respect to fluid intake, voiding and urine leakage will help to identify the symptoms of OAB. For physicians, it is necessary to evaluate the basic and clinical impact and get a detailed patient history to diagnose OAB. In clinical practice, the syndrome of $\mathrm{OAB}$ can be defined as a condition which is characterized by urinary urgency, with or without urge incontinence, usually with urinary frequency and nocturia [3]. Debbie Kinsey and colleagues revealed that the patients suffered from $\mathrm{OAB}$ are psychologically very disturbed and lived a lower quality of life than normal people [4]. This review article provides an insight of the neural control, bladder physiology, regulation of micturition in a normal individual and also disrupt the mechanism of micturition in $\mathrm{OAB}$ patients along with the risk factors, prevalence, assessment, management and future perspective of OAB. For this review article, an extensive literature survey was carried out on search engines including Pubmed, Science Direct, Google scholar by referring keywords as subsections mentioned in this article and collect the information available tentatively from year 1980 .

\section{Neural control, bladder physiology and regulation of micturition}

The continuous efforts are taken in order to understand the complex and highly distributed functioning of neural control of urinary bladder and urethra which results in the process of micturition. The role of neural ascendancy on the bladder and urethra are to facilitate urine discharge when the mechanical, emotional and social circumstances are appropriate. The synchronized activities of urinary bladder for urine collection and discharge are managed by the central and peripheral nervous systems which are mediated through multiple neurotransmitter systems [5]. The various parts of the body involved in this coordination are the brain, smooth and striated muscles of the urinary bladder, bladder neck, urethra and urethral sphincter [6, 7]. In brief, during the time of storage of urine in the bladder, the detrusor muscle undergoes destress or unbend while the external urethral sphincter gets contracted and the information related to bladder filling is continuously sent to the central nervous system (CNS). Inversely, during micturition, the bladder contracts and the external urethral sphincter come into relaxation mode, and results in to the discharge of urine [8]. The detailed mechanism of neural control and regulation of micturition are shown in fig. 1. At the top of spinal cord, there is a main control center in the Pons (the part of the brain-stem that links medulla oblongata and the thalamus) where it unswervingly stimulates the bladder neurons. This center restrains the urethral sphincter, which synchronizes bladder contraction and sphincter relaxation and eventually the bladder gets void. The nervous system at several levels regulates the bladder and urethral sphincters, particularly the sacral segments and the Pons. The lower urinary tract (LUT) is innervated by hypogastric, pudendal and pelvic nerves of sympathetic, somatic and parasympathetic nervous systems respectively. These nerves have both afferent as well as efferent axons. The nervous systems involved in efferent and afferent actions lead to urine accumulation and further urine release from the bladder.

In the first stage, the sympathetic innervation is initiated between detrusor and the urethral sphincter. The connection between brain and LUT is at the T10-L2 level of the spinal cord via sympathetic outflow. This innervation provides a noradrenergic inhibitory action at bladder body and excitatory effect at bladder base and proximal urethral sphincter inputs via release of noradrenaline on $\beta_{3}$-adrenergic receptors and $\alpha_{1}$-adrenergic receptors respectively. This results in activation of hypogastric nerve, which persuades the loss of tension of bladder body by $\beta_{3}$ adrenergic receptors and narrow bladder opening and urethra through $\alpha_{1}$-adrenergic receptors. This sympathetic activation contributes for urine storage in the bladder and maintains storage for prolonged time [5, 8-12]. $\beta$-adrenergic receptors are also found in urothelium $[13,14]$. During the urine storage phase, the volume 
of apical umbrella cells enhances the stretching of the bladder muscle. At the same time some mediators release and excite the sensory fibers [15]. In the second stage, the striated urethral sphincter (SUS) is innervated by somatic motor neurons which are located in Onuf's nucleus $[6,16]$. Pudendal nerves appear from S2S4 levels that excite the distal SUS. Activation of sacral somatic nervous system results in tightening of SUS. In the third stage, pelvic nerves which are the part of the parasympathetic nervous system are responsible for release of excitatory transmitter acetylcholine binds to M3 muscarinic receptor which provokes the contraction of bladder and relaxation of urethra. This contributes to urinary bladder emptying $[9,17]$. In additional mechanism, adenosine triphosphate (ATP) binds to $\mathrm{P}_{2} \mathrm{X}_{1}$ purinergic receptors on detrusor muscle and leads to contraction $[9,18]$. The inhibition of the urethral smooth muscles may also happen due to nitric oxide, which is released through parasympathetic nerves [19]. As reported earlier sympathetic, somatic and parasympathetic nervous systems exert an action by both efferent and afferent axons. Afferent axon transmits the sensation from LUT to the spinal cord. Sensations of bladder fullness due to increase in volume and wall tension, are transmitted to the spinal cord by the hypogastric and pelvic nerves $[6,20]$, while the pudendal and hypogastric nerves, specifically the sensory input are passed through the bladder neck and urethra. Moreover, the pelvic afferent nerve consists of two fibers myelinated $A \delta$ axons and unmyelinated $C$ fibers. The myelinated $A \delta$ axons are sensitive to unreceptive expansion and dynamic tightening [20] and hence transmit the information of the bladder filling whereas the unmyelinated $C$ fibers react actively to noxious stimuli for cooling [21] or chemical irritation [22]. In a physiological condition such as spinal cord injury (SCI), these unmyelinated $\mathrm{C}$ fibers are not sensitive to bladder filling. In periaqueductal grey matter (PAG), middle pons and frontal lobe area, it was observed that the improvement in the brain activity relates to the bladder volume [23]. The coordination of efferent and afferent actions revealed that after filling the urinary bladder, the afferent signals from the receptors in the wall of the bladder and the urothelium are promulgated towards higher point of PAG $[23,24]$ through the sacral spinal cord [25]. A switching action is activated when these afferent indications attain an adequately high intensity and subsequently increase the efferent signals which move down via the spinal cord and stimulate the sacral sections. This leads to the detrusor contraction and also endorses urethral sphincter relaxation which ultimately initiates micturition. Afferent neurons will carry on conflagration and empty the bladder till it gets completely vacant [5].

\section{OAB}

The normal function of LUT is characterized by the capacity to stay incontinence during urine accumulation and emptying bladder as per the individual convenience after receiving the sensation of bladder fullness. Such function is controlled by neural and micturition regulation mechanism. Interruption in these organized functions lead to irregular urine accumulation and discharge. The disturbances in the afferent nerve regulation of bladder function will affect the urine storage and emptying system coordination [26]. The indications of $\mathrm{OAB}$ are urgency, frequency, nocturia and urge urinary incontinence $[2,3]$. There are three different causes of $\mathrm{OAB}$ such as neurogenic, non-neurogenic and idiopathic. In neurogenic etiology, most of CNS conditions such as stroke, Parkinson's disease, traumatic brain injury, multiple sclerosis (MS), SCI, etc. have been associated. In non-neurogenic etiology, bladder outlet obstruction, bladder infection, chronic cystitis, bladder cancer, bladder stone, etc. are associated with OAB with respect to age [3]. Smooth muscles of urinary bladder are known as detrusor muscles and comprised of body or dome and base. $\beta$-adrenergic and cholinergic receptors are predominantly present at the dome, while $\alpha$-adrenergic receptors are located at the base and the proximal urethra [17, 27]. The parasympathetic motoneurons are responsible for release of excitatory neurotransmitter acetylcholine, and interact with the muscarinic receptors. This results to tightening of bladder muscle and relax urethra which leads to the bladder emptying [9]. Amongst the 5 muscarinic receptors, subtypes M2 and M3 are the principle receptors sited on the bladder, whereas M3 receptors are overriding for the tightening of the detrusor muscle [17, 28]. During bladder enlargement there is an overstated effect of released acetylcholine from the urothelium. Subsequently, response to CNS generates the feeling of urgency, premature triggering and also promotes the symptoms of $O A B$ [29]. It is also observed that a component in muscle or tissue rather than the nerve impulses feel the sensation for involuntary rise in the bladder pressure [30]. In the $\mathrm{OAB}$ syndrome, urinary bladder won't be full but detrusor overactivity and external urethral sphincter will promote the release of urine by creating a sensation of urgency $[31,33]$. The detailed mechanism is illustrated in fig. 1.

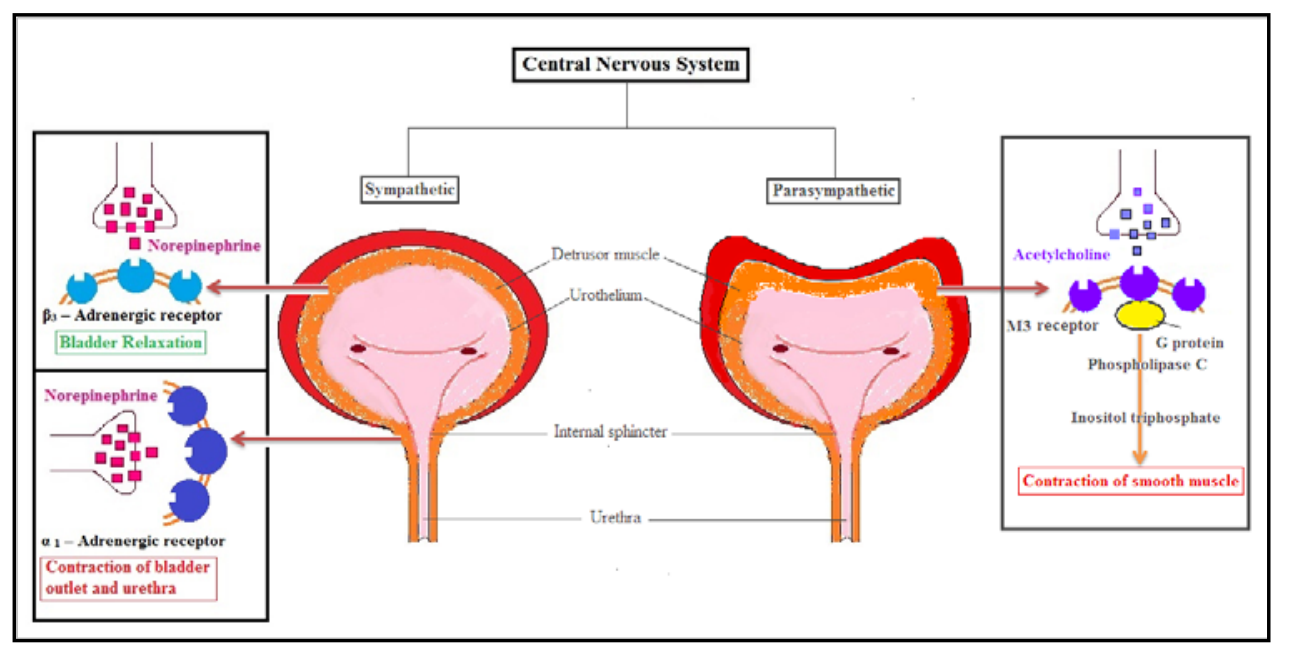

Fig. 1: Mechanism of neural control on contraction and relaxation of smooth muscle

\section{Factors responsible for risk of $\mathrm{OAB}$}

Problems associated with urinary tract infections may lead to impermanent bladder symptoms, which are recoverable. Progressive age is a prominent factor which is more likely to contribute in $\mathrm{OAB}$ symptoms. Other reasons for $\mathrm{OAB}$ are neurological changes; the drag of gravity or weight may cause pelvic base organs to prolapse and susceptible to urinary tract infection because of the weaker immune system [34-36]. In women, a significant drop in estrogen level observed after menopause, which results in thinner and drier tissues of bladder, urethra, and pelvic muscle atrophy may be the cause that leads to urgency and 
frequency of urination [37]. Some conditions like pregnancy and childbirth, disease of the nervous system, bladder cancer, pelvic surgery, enlargement of the prostate, urinary tract infection, overweight, medications like diuretics, sedatives, antidepressants, certain occupations like teaching, nursing, police officers, truck/bus driving, etc. may cause the risk of OAB.

\section{Prevalence of $\mathrm{OAB}$}

Progressive age is a primary cause for the increase in the prevalence of $\mathrm{OAB}[36,38,39]$. As per Milsom, $\mathrm{OAB}$ symptoms are more prevalent in European countries like France, Germany, Italy, Spain, Sweden and UK using a random and stratified approach [36]. In this study, the general population of men and women aged over and equal to $40 \mathrm{y}$ were selected and younger women showed more $\mathrm{OAB}$ signs than men whereas the reverse condition was observed in the aged population. There was no significant difference in the overall prevalence reported in women and men of $16.9 \%$ and $16.0 \%$ respectively when compared the complete population of both. In these six European countries total 22 million people will be suffered from $\mathrm{OAB}$ if extrapolated to the total population of above $40 \mathrm{y}$ of age. Irwin conducted a separate study which estimates globally and specific area of a base number of people suffered from $O A B$ in 2008 and predicted for 2018 with the support of their own EPIC study [1]. EPIC study was a telephonic survey of 19,165 men and women in 5 regions [38]. According to this study in 2008, 455 million people experienced $\mathrm{OAB}$ worldwide and an anticipated increase to 546 million (20.1\%) till 2018. In 2008, the global prevalence was more in women $(11.6 \%)$ than men $(9.7 \%)$ and also anticipated the similar way in 2018 (11.9\% vs $10.0 \%)$. Asia is the most OAB affected region than Europe followed by Africa, North America and South America. From 2008 to 2018, there will be an increase in OAB patients in Asia, South America and Africa as $22.1 \%, 22.4 \%$ and $31.1 \%$ respectively. Based on the published economic model [40], it was extrapolated that the normal global yearly treatment cost of $\mathrm{OAB}$ will be $€ 1.4$ trillion to $€ 3.2$ trillion by 2018 [1]. Other than EPIC and Milsom study, some other studies were also conducted by some agencies on the prevalence of OAB like National Overactive Bladder Evaluation study and The Epidemiology of Lower Urinary Tract symptoms [35].

\section{Evaluation and diagnosis}

The patient's history is of prime importance to elicit the symptoms of OAB. The physician considers the LUTS, any medical condition related to $\mathrm{OAB}$, dietary habits, bladder storage and emptying associated with $\mathrm{OAB}$, ongoing medication, current or past surgical problem, any radiation treatment for lower body cancer, physical examination (Body mass index, abdomen, genitalia, relevant pelvic examination, neurologic, mental status), urine analysis, urodynamic testing, post-void residual (PVR) measurement with an ultrasound bladder scanner, urine cytology, cystoscopy etc. There must be check on the of observable urinary tract disease. In normal healthy patients the range of frequency is four to eight voids per $24 \mathrm{~h}$, thus additional voids may be significant to assess OAB. The information to be received from the patient through questionnaire should include number of voids in a day divided as daytime and nighttime, amount of urine over $24 \mathrm{~h}$, utmost discharged urine amount, average and highest urine amount, and night-time urine amount. An evaluation of lack of voluntary control over urination in terms of seepage episodes and usage of can also be obtained. The overall history, monitoring, test outputs will help to a physician for the evaluation of $\mathrm{OAB}$ and accordingly set the treatment approaches $[2$, $35,41-44]$.

\section{Treatment for $\mathrm{OAB}$}

\section{Lifestyle intervention, behavioral treatments, bladder training}

After receiving the information from the patient through questionnaire and the regular monitoring activities through the bladder diary, the physician may initiate the treatment based on the intensity and the cause of $\mathrm{OAB}$. The lifestyle intervention includes altering fluid intake, smoking termination, avoid bladder irritants like organic and carbonated beverages, coffee, body weight reduction, adapting bowel role to avoid constipation and spraining during bowel movements and sleeping time [35, 41, 42]. In behavioral treatment, the patient has to be trained in improving the control to restrain or disrupt detrusor tightening. To manage the seepage of urine, a deliberated pelvic floor muscle tightening should be practiced which makes possible to get better stress within the urethra and hinder the detrusor tapering. In the elderly population after the physical examination training for two seconds as mentioned above with fifteen replication has to be scheduled and this should be followed thrice a day. The patient should progressively increase this practice by almost one second every week, till they attain ten second tightening and relaxations. Gradually the patient is trained to uphold the urination in such a way that, whenever he/she feels the urgency, rather than running to the washroom, individual waits and calms down and squeezes the pelvic floor muscles exclusively until the pressure is gone. The practice of walking towards the washroom at regular speed should be repeated whenever the sense of urgency arises. Trained professional shall instruct the patient for at least 3 mo to see the benefits of these instructions [41, 42, 44, 45]. In the bladder training program after reviewing the bladder diary of a patient, the physician has scheduled the longest comfortable interval between voiding the bladder in object to reduce its frequency. The patient is trained to empty the bladder after awakening, then at a pre-scheduled time of the whole day and finally before going to bed. In case if the sense of urgency occurs between prefix intervals, the patient is trained to tighten the pelvic floor muscles until the schedule voiding time have been reached. After 1-2 w, the patient is trained for gradually increasing time distance between the urination. During this training the patients are encouraged to sit down in urgency, take slow, deep breaths and concentrate on breathing instead of bladder sensation $[42,46]$. For the above mentioned programs, the exercises must be completed daily with motivation to patience. If these measures fail to control the symptoms, then anticholinergic medications are added $[33,38,43]$.

\section{Anticholinergic or antimuscarinics drug}

As described in the first section of this review, the parasympathetic postganglionic nerves, releases neurotransmitter acetylcholine, this binds to the muscarinic receptor M3 on the detrusor muscle which results to the contraction of the bladder $[9,18]$. In $\mathrm{OAB}$ patient, during the bladder filling, the anticholinergic drugs competitively inhibit acetylcholine binding to M3 receptor as shown in fig. 1 and avoid instinctive tightening of the bladder. Secondly, anticholinergic drugs inhibit potentially urothelial sensory receptors and decrease afferent nerve activity, i.e. sensory inputs from the bladder [41, 42, 47-51]. These drugs enhance the capacity of the bladder at the first automatic contraction response $[2,47,52]$. Since the anticholinergic drugs act competitively, the immense discharge of acetylcholine during urination will curtail the active moiety consequence and detrusor muscle squeezes [42]. The selective anticholinergic drugs have more affinity for the $\mathrm{M} 3$ receptor and therefore may reduce the side effects associated with these drugs [35].

Commonly used anticholinergic drugs are oxybutynin, darifenacin, solifenacin, tolterodine, fesoterodine, trospium, flavoxate, propantheline, propiverine [1, 32, 35, 41, 42, 53]. Flavoxate [2] and propantheline $[54,55]$ are considered as the antispasmodic drug with anticholinergic activity. Flavoxate acts by involving intracellular cAMP accumulation and calcium obstructive action. It restrains the bladder tightening persuaded by different agonists or by electrical stimulation and decrease the occurrence of the bladder emptying. It enhances the bladder space capability and decreases urination pressure [56]. Propiverine inhibits the calcium invasion and modulates calcium of intracellular in urinary bladder smooth muscle cells causing musculotropic spasmolysis.

Due to anticholinergic action it also inhibits the efferent correlation of the nervous pelvicus [57]. Constipation and dry mouth are two most common adverse effects of the anticholinergics. Amongst the aged individuals serious side effects of antimuscarinics are cognitive deficits and confusion along with CNS effects such as insomnia, dizziness, sedation $[2,35,41,42]$. After initiation of the therapy, careful management is required considering side effects, dose, dosage form, and pharmacokinetic-pharmacodynamic of individual drug [42]. 


\section{$\beta_{3}$-adrenergic agonist drug}

During the urine storage phase in the bladder, the sympathetic nerves release norepinephrine (noradrenaline) which binds to the $\beta_{3}$-adrenergic receptors on the detrusor muscle. It also provides inhibitory action resulted in a relaxation of the bladder $[5,8,9]$. The single and only approved drug mirabegron acts as a potent and selective $\beta_{3}$-adrenoceptor agonist as demonstrated by in vitro laboratory experiments. In mammalian species, it relaxes the smooth muscle of the bladder through the increased cAMP concentrations in the tissue. In $\mathrm{OAB}$ rat models, mirabegron enhances the average emptiness volume per urination, reduces the frequency of non-voiding tightening and increases the bladder capacity without disturbing discharge stress and enduring urine volume. Mirabegron illustrates decreased annulled incidence. Hence, mirabegron can be used in patients who stop the previous anticholinergic therapy [58-61]. Some of the common side effects of mirabegron are tachycardia, urinary tract infections, nausea, constipation, headache, diarrhea, dizziness and uncommon or irregular heartbeat, increased blood pressure, angioedema [62, 63].

\section{Other agents}

\section{Desmopressin acetate}

It is a synthetic analogue of antidiuretic hormone (ADH) vasopressin which is formed by the hypothalamus and preserved in the posterior pituitary gland $[2,64]$. The primary role of $\mathrm{ADH}$ is to control extracellular fluid volume in the body. Desmopressin acts on the kidneys by reducing the amount of urine produced at night and also responsible for re-absorption of water by kidney $[65,66]$. Desmopressin acts by imitating the ADH role. Due to hyponatremia, the nasal dosage form is no more indicated for primary enuresis [2, $65,67]$. As such desmopressin is a safe medicine with less side effects such as a headache, stomach ache and occasional emotional disturbance [68].

\section{Tricyclic antidepressants}

Imipramine and amitriptyline have been used for $\mathrm{OAB}$ treatment due to their multiple actions as an anticholinergic as well as an alpha-agonist action $[2,69,70]$. Their antimuscarinic activity is feebler than the others of the same category. There is a limitation of imipramine use amongst the old aged patients for OAB syndrome [70]. However, it has been mentioned that due to the central effect of the automatic emptiness, imipramine has been suggested to combine with the urge-stress incontinence especially in older women [34]. The side effects observed are vast including dry mouth, constipation, stomach pain, nausea, cardiac arrhythmias, urinary retention and drowsiness [35].

\section{Invasive therapies}

When patients are not responding to the medications and therapies, the physician may offer a highly specialized and expensive therapy such as Bolulinum toxin A. In most of the cases, tolerability can be limited due to significant side effects, although in some cases it shows a significant clinical success. Following are the invasive therapies used to treat severe $\mathrm{OAB}$ condition.

\section{Botulinum toxin $A$}

This is a strong neurotoxin formed by Clostridium botulinum. It works by restraining the calcium intervened discharge of acetylcholine at the pre-synaptic neuromuscular intersection in peripheral nerve endings and facilitates in impermanent flaccid muscle paralysis [71, 72]. This binding of the toxin to the peripheral and central nerve ending is well discriminated [73]. The molecule gets absorbed by attaching to the neuronal cell membrane with the heavy chain $[72,74]$. Then a disulfide reaction disconnects the heavy and the light chain. The free light chain attached to the acetylcholine vesicles performs as a zinc-dependent endopeptidase which divides in numerous proteins required for the combination of neurotransmitter vesicles with the cell shell, and avoids acetylcholine exocytosis and confectioning the neuromuscular end-plate [72, 75]. The reconstituted solution is administered in the bladder through injection via flexible or rigid cystoscope which is kept away from trigone and base. A total of 15 to 20 injections may be required during management of the OAB. Summary of the Product Characteristics of BOTOХ® 100 Units was describing the spot of injections in the urinary bladder [71, 76]. Possible side effects of Botulinum toxin A may include generalized diplopia, blurred vision, dysphasia and weakness.

\section{Neuromodulator implants}

Sacral neuromodulation is an operative treatment for individuals with refractory OAB. Tanagho and Schmidt are the pioneers of this surgery in which an electrode is to be implanted in the S3-S4 sacral foramen to create persistent electric sacral nerves activation and reinstate normality for emptying behavior [77]. Basically, this surgery is divided into two stages, in the first phase the efficacy of implantation has been demonstrated and then second phase follows permanent implantation. A tinned quadripolar lead is inserted through the skin into the S3 foramen using bony landmarks and fluoroscopic guidance. The nerve core is stimulated electrically to judge the position. To evaluate the correct placement of quadripolar lead there are some responses to be observed in the toes, rectum, labia, penis and vagina. An external pulsate maker is coupled to the quadripolar lead after positioning in S3 foramen which has the ability to alter the activation force, frequency and pulse width. Fifty percent or more cure in $\mathrm{OAB}$ condition is the criteria for device or it should be removed if no improvement is observed $[78,79]$. Although the considerable use of sacral neuromodulator is observed in past decades, the exact mechanism remains feebly illuminated. Leng and Chancellor have stated that the automatic urination is caused due to the activation of the unmyelinated $\mathrm{C}$ fibers and alpha-myelinated afferent fibers in pelvic and pudendal nerve roots [80]. Electric stimulations produced by sacral neuromodulator stimulate the pacemaker of the bladder and are capable of restraining the neural reflexes [81]. According to the additional mechanism, the sacral neuromodulator imparts straight hindering efforts to the bladder, which repress $\mathrm{OAB}$ and develops urinary withholding [82]. There are number of complications noted due to the neuromodulator implants which need surgical correction involves the relocation of the device due to pain. The most commonly observed side effects are pain at stimulator site, pain due to misplacement of lead, temporary electric shock [83]. It is used in pregnancy, but remains unclear and undetermined whether associated with teratogenic effect. Overall, this is a complicated treatment and adverse events are dependent on the type of complication [79].

\section{Augmentation cystoplasty}

An augmentation cystoplasty (AC) is a surgical operation for bladder enlargement (increasing the size of the bladder). Bladder augmentation was found to be useful, especially with underlying neurological disorders such as SCI, MS and myelodysplasia. Detubularised patch of the ileum is the most frequently used bowel segments for AC. While ileum is not suitable for augmentation, sigmoid colon is the most common alternative. Augmentation caecocystoplasty (the caecum) and augmentation gastrocystoplasty (the stomach) can also be used in this surgical procedure [84]. The results of both autoaugmentation and ureterocystoplasty are either poor [85] or revision of surgery is required [86]. The AC involves there is a high risk of complications such as prolonged postoperative ileus, transient urinary fistula, wound infection, bleeding which requires reoperation, metabolic complications, acid-base and electrolyte disturbances, haematuria-dysuria syndrome in gastrocystoplasty, peptic ulceration and/or perforation of the bladder, urinary stone formation after augmentation, potential increased risk of malignancy, bowel disturbance and urologic surgery after AC [84].

\section{New drug delivery system (NDDS) for urinary bladder diseases}

The conventional drug delivery system may lead to the fast absorption from gastrointestinal tract resulting to minimum efficacy with side effects of the drug. The long-acting targeted drug delivery system is used for treatment or management of OAB syndrome with fewer side-effects and better patient compliance. Table 1 illustrates the NDDS available or under development for the drug delivery to treat $\mathrm{OAB}$ syndrome. 
Table 1: Different NDDS dosage forms with their applications

\begin{tabular}{|c|c|c|c|c|c|}
\hline S. No. & Drug name & NDDS & Application & Remark & References \\
\hline 1 & $\begin{array}{l}\text { Botulinum neurotoxin } \\
\text { serotype } A \text { (BoNT-A) }\end{array}$ & Liposome & $\mathrm{OAB}$ & $\begin{array}{l}\text { Modulate afferent neurotransmission } \\
\text { by penetrating in urothelium }\end{array}$ & 87 \\
\hline 2 & Oxybutynin & Iontophoresis & $\mathrm{OAB}$ & $\begin{array}{l}\text { Enhancement of transdermal drug } \\
\text { transport }\end{array}$ & 88 \\
\hline 3. & Tacrolimus & Liposome & $\begin{array}{l}\text { Prophylaxis of transplant } \\
\text { rejection }\end{array}$ & $\begin{array}{l}\text { Systemic side effects are minimum } \\
\text { since locally acting }\end{array}$ & 89 \\
\hline 4. & Epirubicin & $\begin{array}{l}\text { Polymeric } \\
\text { nanoparticles }\end{array}$ & In range of neoplastic conditions & $\begin{array}{l}\text { Improved penetration in to bladder } \\
\text { wall }\end{array}$ & 90 \\
\hline 5. & Doxorubicin & $\begin{array}{l}\text { Magnetic } \\
\text { nanoparticles }\end{array}$ & In cancer treatment & Diffusion occurs in the bladder wall & 90 \\
\hline 6. & Nanocrystal & $\begin{array}{l}\text { Nanocrystalline } \\
\text { silver }\end{array}$ & $\begin{array}{l}\text { Decrease bladder cancer necrosis } \\
\text { factor- } \alpha \text {, urine histamine and } \\
\text { mastcyte activaion with no lethal } \\
\text { effect. }\end{array}$ & Introduced intravesically & 90 \\
\hline 7. & 5-aminosalicylic acid & $\begin{array}{l}\text { Mucoadhesive } \\
\text { nanoparticles }\end{array}$ & anti-inflammatory & $\begin{array}{l}\text { A derivative of Chitosan i.e. } \mathrm{N} \text { - } \\
\text { sulfonato-N, O-carboxymethyl } \\
\text { chitosan used as a carrier }\end{array}$ & 90 \\
\hline 8. & 5-aminosalicylic acid & Dendrimers & $\begin{array}{l}\text { Decrease the loss of color of a } \\
\text { fluorochrome, protoporphyrin IX } \\
\text { and progress in visibility during } \\
\text { cystoscopy }\end{array}$ & $\begin{array}{l}\text { Core-shell macromolecules having a } \\
\text { high degree of controlled drug-release } \\
\text { pattern }\end{array}$ & 91 \\
\hline \multirow[t]{2}{*}{9.} & Tolterodine & $\begin{array}{l}\text { Transdermal } \\
\text { hydrogel }\end{array}$ & $\mathrm{OAB}$ & $\begin{array}{l}\text { Prolonged pharmacological response } \\
\text { for the treatment of } \mathrm{OAB}\end{array}$ & 92,93 \\
\hline & & $\begin{array}{l}\text { Extended Release } \\
\text { pellets }\end{array}$ & & & 94 \\
\hline
\end{tabular}

\section{CONCLUSION}

The plethora of research illuminates in this review provides information of $\mathrm{OAB}$ and its different therapies like behavioural modification, drug therapy and the combination of both. For the evaluation and initiation of these therapies, a urologist should collect the history of the patient, information about life-style, urination of patient and perform a physical examination, different tests like urine analysis. If the symptoms are not managed by these treatments, then invasive therapies like botulinum toxin $A$ injection, neuromodulator implants, augmentation cystoplasty may be exploited by a physician with complete control and balancing the efficacy and complications or side effects of invasive therapies. In future, researchers have to explore the drug therapies with limited side effects and high beneficial for the patients over an available class of drugs. Antimuscarinics are mostly used as first-line therapy, but showed many side effects due to less receptor selectivity. Hence, it is necessary to investigate more selective antimuscarinic agents. Invasive therapies are slowly getting popular in $\mathrm{OAB}$ patients despite of more complications than efficacy percentage. Investigators are needed to pay an attention for decreasing the complications and side effects of these therapies and simultaneously improving the relief ratio. Moreover, educational resources should be provided to the people for creating awareness, especially in women population to let them understand the issue and accordingly the healthcare services can be provided.

\section{AUTHORS CONTRIBUTIONS}

Both the authors namely Pankaj Mandpe and Bala Prabhakar were involved equally in literature survey, framing contents, writing draft paper and finalizing the review paper.

\section{CONFLICTS OF INTERESTS}

Authors declared that there are no potential conflicts of interest.

\section{REFERENCES}

1. Irwin DE, Kopp ZS, Agatep B, Milsom I, Abrams P. Worldwide prevalence estimates of lower urinary tract symptoms, overactive bladder, urinary incontinence and bladder outlet obstruction. BJU Int 2011;108:1132-8.

2. Barkin J. Overactive bladder. Can J Urol 2011;18 Suppl 1:8-13.

3. Blaivas GJ. Overactive bladder and the definition of urgency. Neurourol Urodyn 2007;26:757-8.
4. Kinsey D, Pretorius S, Glover L, Alexander T. The psychological impact of overactive bladder: a systematic review. J Health Psychol 2016;21:69-81.

5. Griffiths D. Neural control of micturition in humans: a working model. Nat Rev Urol 2015;12:695-705.

6. Morrison J, Birder L, Craggs M, De Groat W, Downie J, Drake M et al. Neural control. In: Abrams P, Cardozo L, Khoury S, Wein A. editors. Incontinence. Jersey: Plymouth Health Publications Ltd; 2005. p. 363-422.

7. Fry $\mathrm{CH}$, Brading AF, Hussain M. Cell biology. In: Abrams P, Cardozo L, Khoury S, Wein A. editors. Incontinence. Jersey: Plymouth Health Publications Ltd; 2005. p. 313-62.

8. Holstege G, Mouton LJ. Central nervous system control of micturition. Int Rev Neurobiol 2003;56:123-45.

9. Fowler CJ, Griffiths D, de Groat WC. The neural control of micturition. Nat Rev Neurosci 2008;9:453-66.

10. Yamaguchi $0 . \beta 3$-adrenoceptors in human detrusor muscle. Urology 2002;59(5 Suppl 1):25-9.

11. Andersson KE. Pharmacology of lower urinary tract smooth muscles and penile erectile tissues. Pharmacol Rev 1993;45:253-308.

12. Chancellor MB, Yoshimura N. Neurophysiology of stress urinary incontinence. Rev Urol 2004;6 Suppl 3:S19-28.

13. Otsuka A, Shinbo H, Matsumoto R, Kurita Y, Ozono S. Expression and functional role of $\beta$-adrenoceptors in the human urinary bladder urothelium. Naunyn Schmiedebergs Arch Pharmacol 2008;377:473-81.

14. de Groat WC. The urothelium in overactive bladder: passive bystander or active participant? Urology 2004;64:7S-11S.

15. Lazzeri M. The physiological function of the urothelium-more than a simple barrier. Urol Int 2006;76:289-95.

16. Sasaki M. Morphological analysis of external urethral and external anal sphincter motoneurones of cat. J Comp Neurol 1994;349:269-87.

17. Andersson KE. Advances in the pharmacological control of the bladder. Exp Physiol 1999;84:195-213.

18. Pak KJ, Ostrom RS, Matsui M, Ehlert FJ. The M2-muscarinic receptor inhibits the development of streptozotocin-induced neuropathy in mouse urinary bladder. J Pharmacol Exp Ther 2010;335:239-48.

19. Andersson KE, Arner A. Urinary bladder contraction and relaxation: physiology and pathophysiology. Physiol Rev 2004;84:935-86. 
20. Janig W, Morrison JF. Functional properties of spinal visceral afferents supplying abdominal and pelvic organs, with special emphasis on visceral nociception. Prog Brain Res 1986;67:87-114.

21. Fall M, Lindström S, Mazieres L. A bladder-to-bladder cooling reflex in the cat. J Physiol 1990;427:281-300.

22. Habler HJ, Janig W, Koltzenburg M. Activation of unmyelinated afferent fibres by mechanical stimuli and inflammation of the urinary bladder in the cat. J Physiol 1990;425:545-62.

23. Athwal BS, Berkley KJ, Hussain I, Brennan A, Craggs M, Sakakibara $\mathrm{R}$, et al. Brain responses to changes in bladder volume and urge to void in healthy men. Brain 2001;124:369-77.

24. De Groat WC, Griffiths D, Yoshimura N. Neural control of the lower urinary tract. Compr Physiol 2015;5:327-96.

25. Blok BF, de Weerd H, Holstege G. Ultrasound evidence for a paucity of projections from the lumbosacral cord to the pontine micturition centre or M-region in the cat: a new concept for the organization of the micturition reflex with the periaqueductal gray as a central relay. J Comp Neurol 1995;359:300-9.

26. De Groat WC, Yoshimura N. Afferent nerve regulation of bladder function in health and disease. Handb Exp Pharmacol 2009;194:91-138.

27. Rahn DD, Roshanravan SM. Pathophysiology of urinary incontinence, voiding dysfunction, and overactive bladder. Obstet Gynecol Clin North Am 2009;36:463-74.

28. Ouslander JG. Geriatric considerations in the diagnosis and management of overactive bladder. Urology 2002;60(5, Suppl 1):50-5.

29. Haylen BT, de Ridder D, Freeman RM, Swift SE, Berghmans B, Lee J, et al. An International Urogynecological Association (IUGA)/International Continence Society (ICS) joint report on the terminology for female pelvic floor dysfunction. Neurourol Urodyn 2010;29:4-20.

30. Brading AF. A myogenic basis for overactive bladder. Urology 1997;50:57-67.

31. Abrams P. Describing bladder storage function: overactive bladder syndrome and detrusor overactivity. Urology 2003;62 Suppl 5B:28-37.

32. Gillespie JI. Modulation of autonomous contractility activity in the isolated whole bladder of the guinea pig. BJU Int 2004;93:393-400.

33. Abrahms P, Andersson KE. Muscarinic receptor antagonists for overactive bladder. BJU Int 2007;100:987-1006.

34. Ouslander JG. Management of overactive bladder. N Engl J Med 2004;350:786-99.

35. Eapen RS, Radomski SB. Gender differences in overactive bladder. Can J Urol 2016;23 Suppl 1:2-9.

36. Milsom I. Overactive bladder: current understanding and future issues. Br J Obstet Gynaecol 2006;113 Suppl 2:2-8.

37. Tomaszewski J. Postmenopausal overactive bladder. Prz Menopauzalny 2014;13:313-29.

38. Irwin DE, Milsom I, Hunskaar S, Reilly K, Kopp Z, Herschorn S, et al. Population-based survey of urinary incontinence, overactive bladder, and other lower urinary tract symptoms in five countries: results of the EPIC study. Eur Urol 2006;50:1306-15.

39. Dambros M, Dambros MC, Lorenzetti F, Ferreira FT, Palma PCR. Understanding the pathophysiology of the overactive bladder in elderly through the study of a specific muscle blocker on the bladder contractions. J Gerontol Geriatr Res 2016;5:270.

40. Irwin DE, Mungapen L, Milsom I, Kopp Z, Reeves P, Kelleher C. The economic impact of overactive bladder syndrome in six western countries. BJU Int 2009;103:202-9.

41. Marinkovic SP, Rovner ES, Moldwin RM, Stanton SL, Gillen LM, Marinkovic CM. The management of overactive bladder syndrome. Br Med J 2012;344:38-44.

42. Arnold J, McLeod N, Thani-Gasalam R, Rashid P. Overactive bladder syndrome: Management and treatment options. Aust Fam Physician 2012;41:878-83.

43. Gormley EA, Lightner DJ, Burgio KL, Chai TC, Clemens JQ Culkin DJ, et al. Diagnosis and treatment of overactive bladder (non-neurogenic) in adults: AUA/SUFU guideline. J Urol 2012;188:2455-63.

44. Bilal C, Robert L, Elise D. Choice of antimuscarinic agents for overactive bladder in the older patient: focus on darifenacin. Clin Interv Aging 2008;3:503-9.
45. Burgio KL, Locher IL, Goode PS. Combined behavioral and drug therapy for urge incontinence in older women. J Am Geriatr Soc 2000;48:370-4

46. Roe B, Ostaszkiewicz J, Milne J, Wallace S. Systematic reviews of bladder training and voiding programmes in adults: a synopsis of findings from data analysis and outcomes using metastudy techniques. J Adv Nurs 2007;57:15-31.

47. Yokoyama O, Yusup A, Miwa Y, Oyama N, Aoki Y, Akino H. Effects of tolterodine on an overactive bladder depend on suppression of C-fiber bladder afferent activity in rats. J Urol 2005;174:2032-6.

48. Hedlund P, Streng T, Lee T, Andersson KE. Effects of tolterodine on afferent neurotransmission in normal and resiniferatoxintreated conscious rats. J Urol 2007;178:326-31.

49. De Laet K, De Wachter S, Wyndaele JJ. Systemic oxybutynin decreases the afferent activity of the pelvic nerve of the rat: new insights into the working mechanism of antimuscarinics. Neurourol Urodyn 2006;25:156-61.

50. Iijima K, De Wachter S, Wyndaele JJ. Effects of the M3 receptor selective muscarinic antagonist darifenacin on bladder afferent activity of the rat pelvic nerve. Eur Urol 2007;52:842-7.

51. Boy S, Schurch B, Nehring G, Knapp P, Karsentry G, Reitz A. The effect of tolterodine on sensations evoked by electrical stimulation and bladder filling sensations. Eur Urol Suppl 2006;5:223.

52. Andersson KE. Antimuscarinics for the treatment of overactive bladder. Lancet Neurol 2004;3:46-53.

53. Sai Pravin P, Devala Rao G, Jagathi V, Shaiba M, Manohar Babu $\mathrm{CH}$. Spectroflourimetric method for the estimation of darifenacin in pure and pharmaceutical formulations. Asian J Pharm Clin Res 2011;4:44-6.

54. The electronic Medicines Compendium [Internet]. ProBanthine tablets. Summary of Product Characteristics; Available from https://www.medicines.org.uk/emc/printdocument?documentId=18550. [Last accessed on 28 Dec 2017]

55. Barry J, McKay J, Fisher M. Propantheline. Prac Diab 2017; 34:104-5.

56. The electronic Medicines Compendium [Internet]. Urispas $200 \mathrm{mg}$ Film-coated Tablets. Summary of Product Characteristics. Available from: https://www.medicines.org.uk/emc/print-document? documentId=19613. [Last accessed on 30 May 2016]

57. The electronic Medicines Compendium [Internet]. Detrunorm XL $30 \mathrm{mg}$ Modified Release Capsules. Summary of Product Characteristics. Updated on 2016 Mar 18. Available from: https://www.medicines.org.uk/emc/printdocument?documentId=18501. [Last accessed on 30 May 2016]

58. Sacco E, Bientinesi R. Mirabegron: a review of recent data and its prospects in the management of overactive bladder. Ther Adv Urol 2012;4:315-24.

59. Sacco E, Bientinesi R. Mirabegron, a novel, non-antimuscarinic drug for the overactive bladder: an up-to-date review. World J Obstet Gynecol 2013;2:65-73.

60. Sacco E, Bientinesi R, Tienforti D, Racioppi M, Gulino G, D'Agostino D, et al. Discovery history and clinical development of mirabegron for the treatment of overactive bladder and urinary incontinence. Expert Opin Drug Discovery 2014;9:1-16.

61. Badawi JK, Uecelehan H, Hatzinger M, Michel MS, Haferkamp A, Bross S. Relaxant effects of beta-adrenergic agonists on porcine and human detrusor muscle. Acta Physiol Scand 2005;185:151-9.

62. The electronic Medicines Compendium [Internet]. Betmiga 25 $\mathrm{mg}$ and $50 \mathrm{mg}$ prolonged-release tablets. Summary of Product Characteristics. Available from https://www.medicines. org.uk/emc/medicine/27429. [Last Accessed on 15 Apr 2016]

63. Drugs@FDA: FDA Approved Drug Products [Internet]. MYRBETRIQ-Mirabegron $25 \mathrm{mg}$ and $50 \mathrm{mg}$ tablet, film coated, extended release. Highlights of Prescribing Information. Available from:https://www.accessdata.fda.gov/scripts/cder/daf/index.cfm ? event=overview.processandApplNo=202611. [Last accessed on 16 Aug 2016].

64. Dinan TG, O'Brien S, Lavelle E, Scott LV. Further neuroendocrine evidence of enhanced vasopressin V3 receptor responses in melancholic depression. Psychol Med 2004; 34:169-72. 
65. Cachat F. Synthetic DDAVP for nocturnal enuresis and the risk of symptomatic hyponatremia: which treatment now? Which form? Paediatrica 2007;18:54-6.

66. Aladjem M, Wohl R, Boichis H, Orda S, Lotan D, Freedman S. Desmopressin in nocturnal enuresis. Arch Dis Child 1982;57:137-40.

67. Robson WL, Leung AK, Norgaard JP. The comparative safety of oral versus intranasal desmopressin for the treatment of children with nocturnal enuresis. J Urol 2007;178:24-30.

68. O'Flynn N. Nocturnal enuresis in children and young people: NICE clinical guideline. Br J Gen Pract 2011;61:360-2.

69. Geoffrion R, Lovatsis D, Walter JE, Chou Q, Easton W, Epp A, et al. Treatments for overactive bladder: focus on pharmacotherapy. J Obstet Gynaecol Can 2012;34:1092-101.

70. Roxburgh C, Cook J, Dublin N. Anticholinergic drugs versus other medications for overactive bladder syndrome in adults. Cochrane Database Syst Rev 2007:CD003190.

71. Orasanu B, Mahajan ST. The use of botulinum toxin for the treatment of overactive bladder syndrome. Indian J Urol 2013;29:2-11.

72. Hsieh PF, Chiu HC, Chen KC, Chang CH, Chou ECL. Botulinum toxin a for the treatment of overactive bladder. Toxins 2016;8:1-12.

73. Simpson L. Kinetic studies on the interaction between botulinum toxin type $\mathrm{A}$ and the cholinergic neuromuscular junction. J Pharmacol Exp Ther 1980;212:16-21.

74. Dolly J, Black J, Williams R, Melling J. Acceptors for botulinum neurotoxin reside on motor nerve terminals and mediate its internalisation. Nature 1984;307:457-60.

75. Mahajan ST, Brubaker L. Botulinum toxin: from a lifethreatening disease to novel medical therapy. Am J Obstet Gynecol 2007;196:7-15.

76. The electronic medicines compendium [Internet]. BOTOX 100 Units. Summary of Product Characteristics. Available from: https://www.medicines.org.uk/emc/medicine/112. [Last accessed on 14 Mar 2017].

77. Tanagho EA, Schmidt RA. Electrical stimulation in the clinical management of the neurogenic bladder. J Urol 1988;140:1331-9.

78. Sanford MT, Suskind AM. Neuromodulation in neurogenic bladder. Transl Androl Urol 2016;5:117-26.

79. Sukhu T, Kennelly MJ, Kurpad R. Sacral neuromodulation in overactive bladder: a review and current perspectives. Res Rep Urol 2016;8:193-9.

80. Leng WW, Chancellor MB. How sacral nerve stimulation neuromodulation works. Urol Clin North Am 2005;32:11-8.
81. Spinelli MS, Sievert KD. Latest technologic and surgical developments in using inter stim therapy for sacral neuromodulation: impact on treatment success and safety. Eur Urol 2008;54:1287-96.

82. Kohli N, Patterson D. InterStim therapy: a contemporary approach to overactive bladder. Rev Obstet Gynecol 2009;2:18-27.

83. Siegel SW, Catanzaro F, Dijkema HE, Elhilali MM, Fowler CJ, Gajewski JB, et al. Long-term results of a multicenter study on sacral nerve stimulation for treatment of urinary urge incontinence, urgency-frequency, and retention. Urology 2000;56(6 Suppl 1):87-91.

84. Cetinel B, Kocjancic E, Demirdağ C. Augmentation cystoplasty in neurogenic bladder. Investig Clin Urol 2016;57:316-23.

85. Drake MJ, Apostolidis A, Emmanuel A, Gajewski J, Harrison SCW, Heesakkers J, et al. Neurologic urinary and faecal incontinence. In: Abrams P, Cardozo L, Khoury S, Wein A. editors. Incontinence. 5th ed. Paris: ICUD-EAU; 2013. p. 827-954.

86. Johal NS, Hamid R, Aslam Z, Carr B, Cuckow PM, Duffy PG. Ureterocystoplasty: long-term functional results. J Urol 2008;179:2373-5.

87. Janicki JJ, Chancellor MB, Kaufman J, Gruber MA, Chancellor DD. Potential effect of liposomes and liposome-encapsulated botulinum toxin and tacrolimus in the treatment of bladder dysfunction. Toxins 2016;8:1-9.

88. Tyagi P, Wu PC, Chancellor M, Yoshimura N, Huang L. Recent advances in intravesical drug/gene delivery. Mol Pharm 2006;3:369-79.

89. Hung SY, Chancellor DD, Chancellor MB, Chuang YC. Role of the liposome in the treatment of overactive bladder and interstitial cystitis. Urol Sci 2015;26:3-6.

90. Nirmal J, Chuang YC, Tyagi P, Chancellor MB. Intravesical therapy for lower urinary tract symptoms. Urol Sci 2012;23:70-7.

91. Hsu CC, Chuang YC, Chancellor MB. Intravesical drug delivery for the dysfunctional bladder. Int J Urol 2013;20:552-62.

92. El-Sheikh R, Hassan WS, Gouda AA, El-Gabry MM. Sensitive spectrophotometric assay of muscarinic receptor antagonist tolterodine tartrate in bulk drug and pharmaceutical formulations. Asian J Pharm Clin Res 2017;10:346-52.

93. Sun F, Sui C, Zhou Y, Liu X, Shi Y, Wu Y, et al. Preparation, characterization and pharmacological evaluation of tolterodine hydrogels for the treatment of overactive bladder. Int J Pharm 2013;454:532-8.

94. Patil V, Belsare D. Development and evaluation of novel drug delivery system of tolterodine tartrate. Int J Appl Pharm 2017;9:29-32. 